\title{
UM OLHAR A PARTIR DA EPISTEMOLOGIA DE LARRY LAUDAN PARA O ENSINO DE CIÊNCIAS: A RESOLUÇÃO DE PROBLEMAS EM AULAS DE CIÊNCIAS
}

\section{A LOOK FROM LARRY LAUDAN'S EPISTEMOLOGY TO SCIENCE TEACHING: PROBLEM SOLVING IN SCIENCE CLASSES}

\author{
Mara Elisângela Jappe Goi* \\ Ana Flavia Correa Leão**
}

\begin{abstract}
RESUMO: O presente artigo busca pressupostos epistemológicos da área de Ensino de Ciências para balizar a metodologia de Resolução de Problemas. Para isso, fez-se um estudo da epistemologia de Larry Laudan para compreender o avanço da Ciência através do modelo de Resolução de Problemas empíricos e conceituais. Este estudo baseou-se em uma análise de conteúdo das obras de Laudan e de artigos e/ou livros presentes na literatura sobre a sua epistemologia trazendo esclarecimentos plausíveis acerca do processo de construção da Ciência que possam contribuir para 0 aprimoramento das concepções epistemológicas e colaborar para novas estratégias de ensino e a aprendizagem, e formação de cidadãos, a fim de relacionar os conteúdos assimilados a uma sociedade em constante transformação, adquirindo uma visão crítica e autônoma acerca dos fenômenos científicos do meio no qual estão inseridos. A transformação de problemas não resolvidos ou anômalos em problemas resolvidos de forma gradual constitui-se, para Laudan, um progresso científico. Outra marca da proposta de Laudan é a "tradição de investigação", definida como um conjunto de compromissos ontológicos e metodológicos que vão orientar a pesquisa científica e o desenvolvimento de suas teorias específicas. Mesmo tendo críticas sobre sua forma de avaliar os problemas, o progresso científico e as tradições de investigação da ciência, observa-se que as concepções do autor apontam para a consolidação de um embasamento teórico mais elaborado sobre a atividade científica, trazendo critérios importantes para a construção de aulas mais relevantes e sistematizadas de/e sobre Ciências, com modelos de ensino e aprendizagem frutíferos e eficientes. Nesta concepção, aponta-se que os estudantes através do uso da Resolução de Problemas em seus contextos escolares podem aprender os conteúdos do currículo e relacioná-los com suas vivências, Ihes atribuindo significados úteis para suas vidas.
\end{abstract}

Palavras-chave: Epistemologia de Larry Laudan; Ensino de Ciências; Resolução de Problemas.

\footnotetext{
Doutora em Educação pela Universidade Federal do Rio Grande do Sul (UFRGS). Docente da Universidade Federal do Pampa (Unipampa). Contato: maragoi28@gmail.com

** Mestranda em Ensino de Ciências pela Universidade Federal do Pampa (Unipampa). Vicediretora da Escola Estadual de Ensino Médio Nossa Senhora da Assunção e professora da Escola Técnica Estadual Dr. Rubens da Rosa Guedes. Contato: leaoanaflavia5@gmail.com
} 
ABSTRACT: This article seeks epistemological assumptions in the field of Science Teaching to guide the Problem Solving methodology. For this, a study of Larry Laudan's epistemology was made to understand the advance of Science through the empirical and conceptual Problem Solving model. This study was based on a content analysis of Laudan's works and articles and/or books present in the literature about his epistemology, bringing plausible clarifications about the process of construction of Science that can contribute to the improvement of epistemological conceptions and contribute to new teaching and learning strategies, and formation of citizens, in order to relate the contents assimilated to a society in constant transformation, acquiring a critical and autonomous view about the scientific phenomena of the environment in which they are inserted. The transformation of unresolved or anomalous problems into problems solved gradually constitutes, for Laudan, a scientific progress. Another hallmark of Laudan's proposal is the "investigation tradition", defined as a set of ontological and methodological commitments that will guide scientific research and the development of its specific theories. Even with criticisms about his way of evaluating problems, scientific progress and the research traditions of science, it is observed that the author's conceptions point to the consolidation of a more elaborate theoretical basis on scientific activity, bringing important criteria to the construction of more relevant and systematized classes of/and about science, with fruitful and efficient teaching and learning models. In this conception, it is pointed out that students, through the use of Problem Solving in their school contexts, can learn the contents of the curriculum and relate them to their experiences, giving them useful meanings for their lives.

Keywords: Larry Laudan's epistemology; Science teaching; Problem solving.

\section{INTRODUÇÃO}

Na busca de pressupostos epistemológicos para o Ensino de Ciências aponta-se Larry Laudan como alternativa de estudo, embora, segundo Cudmani (1998) sua teoria seja pouco explorada. Na visão de Ostermann et al. (2008), vários estudos baseados nas obras de Laudan $(1984,1986,1990)$ fazem críticas à noção de paradigma, propondo um retorno da racionalidade e sugerindo a análise das teorias científicas vinculada à ideia de tradições de pesquisa. Destaca-se que as ideias de Laudan sobre o Ensino de Ciências com o propósito de favorecer a superação do empirismo em prol da ideia de movimento histórico e filosófico da Ciência que já foram discutidas em outros trabalhos, como de Ostermann et al. (2008) que destacam as tradições de pesquisa quântica. No Ensino de Biologia o trabalho de Braunstein (2011) aponta as tradições de pesquisa mendeliana e, Morini (2010) relaciona a epistemologia de Laudan com o Ensino de Física em três aspectos: i) identificação de um problema relevante; ii) motivação para a busca de uma solução a um problema relevante; iii) 
anomalias e complexidade do processo de mudança de Tradição de Pesquisa e da mudança conceitual.

Filósofos e historiadores como Hempel, Kuhn, Buchdahl, Feyerabend, Popper, Lakatos e Grünbaum contribuíram no percurso de Laudan a fim de constituir o caráter da História e da Filosofia da Ciência contemporânea, fazendo com que seu senso crítico em relação a algumas ideias desses filósofos fosse sadiamente aflorado (LAUDAN, 2010). Ainda, junto com esses filósofos, constituem um grupo de epistemólogos denominados "novos historicistas da Ciência" (NICKLES, 2017), os quais apresentaram concepções epistemológicas contemporâneas que se iniciaram nos finais dos anos de 1950, e que têm em comum a História da Ciência para criticar e rebater as narrativas positivistas da Ciência, bem como os seus movimentos (NICKLES,2017). Nesse sentido, por exemplo, vem sua crítica forte a Popper, quando este epistemólogo defende que uma teoria apenas aproxima-se da realidade, pois Laudan (2010) julga mais coerente abordar o nível de ameaça epistemológica do que as inevitáveis inconsistências que possam apresentar as teorias. Pautando-se assim, no pragmatismo, na racionalidade, em que o progresso científico está embasado na Resolução de Problemas.

Contrário à Popper e a outros epistemólogos, que sugerem que para que uma teoria seja refutada por problemas empíricos anômalos não merece atenção séria, e a Kuhn que preconiza que é a acumulação de um elevado número de anomalias pode levar os cientistas a abandonar o paradigma, Laudan (1986, p. 68) sugere que "o mais natural seria falar do grau de ameaça que as anomalias apresentam à teoria". Assim, para Laudan (1986, p.10):

[...] teorias não devem ser abandonadas pelo fato de apresentarem anomalias ou de não serem aceitas por não serem confirmadas empiricamente; a coexistência de teorias concorrentes é a regra, não a restrição, de modo que sua avaliação é, preliminarmente, uma atividade comparativa.

Nesta ótica, pode-se observar que as ideias de Laudan surgem como uma confrontação à tese kuhniana (KUHN 1971; VILLANI 1986; OSTERMANN, 1996) de incomunicabilidade e incomensurabilidade entre paradigmas e como uma tentativa de salvar a racionalidade da Ciência. É, também, um confronto 
com as ideias de Lakatos (1989), na medida em que Laudan reconhece que as mudanças estão centradas tanto na Resolução de Problemas empíricos quanto dos conceituais, valorizando estes últimos.

Laudan (1986) propõe a metodologia de Resolução de Problemas como base para o avanço da Ciência, tanto para problemas empíricos quanto para os conceituais. Nessa visão epistemológica, "a Ciência progride somente se as novas teorias resolvem mais problemas do que suas predecessoras, de modo que o objetivo da Ciência é o de obter teorias com elevada efetividade na resolução de problemas" (LAUDAN, 1986, p. 11).

Por meio deste trabalho pretende-se resgatar as contribuições de Laudan para o Ensino de Ciências no que tange à sua trajetória acadêmica, à epistemologia, ao progresso da Ciência, à taxionomia dos problemas, sendo eles empíricos e conceituais, às tradições de investigação e às críticas epistemológicas da teoria de Laudan. Busca-se, assim, através de uma análise de conteúdo das obras de Laudan e de artigos e/ou livros presentes na literatura, esclarecimentos plausíveis acerca do processo de construção da Ciência que possam contribuir para o aprimoramento das concepções epistemológicas e colaborar para novas estratégias de ensino e de a aprendizagem, bem como a formação de cidadãos, a fim de relacionar os conteúdos assimilados a uma sociedade em constante transformação, adquirindo uma visão crítica e autônoma acerca dos fenômenos científicos do meio no qual estão inseridos.

\section{LARRY LAUDAN E SEUS PRESSUPOSTOS EPISTEMOLÓGICOS}

Estadunidense nascido em 1945, Larry Laudan formou-se bacharel em Física pela Universidade de Kansas em 1962 e possui mestrado e doutorado, obtendo título de Ph.D em Filosofia na Universidade de Princeton, em 1965. Trabalhou como professor de Filosofia da Ciência e História no período entre 1965 e 1997. Foi o fundador do Departamento de História e Filosofia das Ciências da Universidade de Pittsburgh, e lecionou em várias universidades, entre as quais a University College London, a Universidade de Cambridge e as universidades do Hawaii, de Ilininois, de Melbourne, de Minnesota e de 
Rochester (OSTERMANN et al., 2008). Entre suas obras se destacam Progress and Its Problems (1977); Science and Hypothesis (1981); Science and Values (1984); Science and Relativism (1990) e Beyond Positivism and Relativism (1996). Em 'Progress and Its Problems' (1977), Laudan apresenta a essência de sua epistemologia, a qual demonstra o resgate da racionalidade da Ciência e busca evitar alguns dos pressupostos-chave que produziram o que ele chama de 'colapso da análise tradicional' (OSTERMANN et al., 2008). Atualmente é pesquisador no Instituto de Investigações Filosóficas da Universidade Nacional do México.

Para Laudan (1986), é preciso superar o vínculo entre conservação cumulativa e progresso científico. A ideia de progresso científico sem condensação leva-o a optar pela teoria que se aproxima a resolver o maior número de problemas empíricos importantes, ao mesmo tempo em que gera o menor número de problemas conceituais e anomalias relevantes (LAUDAN, 1986, p. 6). A extinção de problemas conceituais reflete no progresso científico, pois é possível que aconteça a troca de teorias bem confirmadas por outras menos confirmadas, uma vez que solucionem problemas conceituais significativos. Um exemplo disso é o caso do modelo atômico de Bohr, estudado na disciplina de Química, que foi aceito no início da Física Quântica, mesmo sem comprovação empírica, dado que resolvia o problema conceitual da emissão de radiação eletromagnética por corpos acelerados, ajudando a explicar a estabilidade do átomo. No entanto, a visão epistemológica de Laudan não se restringe às competições entre teorias.

Do ponto de vista de Laudan (2011, p. 18) "a Ciência é, acima de tudo, uma atividade de solução de problemas" sendo assim, seu intuito é o de criar teorias com alta taxa de eficiência na Resolução de Problemas. Consequentemente, seu progresso corre à medida que teorias novas possam resolver mais problemas que suas antecessoras (PESA; OSTERMANN, 2002).

Segundo Moreira e Massoni (2011, p. 53-54), Laudan considera que no progresso científico existem alguns "rasgos persistentes", sendo eles i) A troca de teorias científicas não é cumulativa; ii) Teorias não são rechaçadas simplesmente porque apresentam anomalias; iii) Teorias não são aceitas 
simplesmente porque são confirmadas empiricamente; iv) A mudança de teorias e as controvérsias sobre elas são resolvidas mais em bases conceituais do que empíricas; v) Há um espectro de níveis de generalidade das teorias que vai desde leis até marcos conceituais abrangentes; vi) Dadas as notáveis dificuldades semânticas e epistêmicas do conceito de "verdade aproximada" é implausível caracterizar o progresso científico como uma verossimilaridade; e, vii) A coexistência de teorias rivais é a regra, não a exceção, de modo que sua avaliação é, primordialmente, uma atividade comparativa.

No que se refere a Epistemologia de Laudan, mesmo não procurando uma demarcação da Ciência com outros campos do pensamento intelectual, advertese que, normalmente, disciplinas consideradas científicas costumam ser mais progressivas na Resolução de Problemas em razão de suas características metodológicas e ontológicas (SANTOS, 2006).

Para Laudan, o objetivo da Ciência é gerar teorias eficazes na solução de problemas ou modelos científicos para resolver determinadas situações, mesmo entendendo que outros moldes de conhecimentos também resolvem problemas, considera os modelos científicos mais eficientes. Também acredita que uma teoria nova que concebe tudo o que a anterior faz, bem como, traz mais contribuições, esta é superior à antecessora (LAUDAN, 2011).

Segundo Laudan (1986) problemas científicos dividem-se em empíricos e conceituais. Caracteriza os problemas empíricos como aqueles tomados pela comunidade científica como estranhos e que precisam de uma explicação no contexto em que foram tomados, já os problemas conceituais se referem a problemas de inconsistências apresentadas em alguma teoria, ou ambiguidades e circularidades internas, sendo que as teorias são produções humanas que respondem a perguntas de pesquisa. $\mathrm{E}$, define anomalia como casos em que a teoria descreve de forma insatisfatória uma determinada situação, necessitando de uma teoria própria. Laudan (1986) não outorga à produção de anomalias a função da Ciência mesmo reconhecendo sua importância, contrariando Popper. Para Laudan, assim como para Kuhn, as anomalias podem levar um paradigma à crise, no entanto, em algumas circunstâncias elas podem ser admitidas e suportadas. 
Conforme Laudan (1986, p. 104), compreende-se que as teorias são desenhadas e corroboradas diante a sua adequação para a solução de problemas empíricos e conceituais, o uso da classe "teoria científica" pode apresentar uma variedade proposicional na sua utilização. Assim, seu uso pode denotar tanto um conjunto específico de doutrinas relacionadas, como axiomas, hipóteses ou princípios, quanto um conjunto de doutrinas mais gerais e menos corroboradas empiricamente, como por exemplo, a teoria da evolução e a teoria cinética dos gases. Outra marca da proposta de Laudan (1986, p. 114) trata-se da formulação da categoria chamada "tradições de investigação", definida como um conjunto de compromissos ontológicos e metodológicos que podem orientar a pesquisa científica e o desenvolvimento de suas teorias específicas.

\section{LARRY LAUDAN E O PROGRESSO CIENTÍFICO}

Há três situações que permitem analogias entre o progresso científico à concepção da epistemologia de Laudan e a aprendizagem de Ciências. A primeira se refere ao reconhecimento de um problema relevante; a segunda ao entusiasmo para a busca de uma solução de um problema relevante e a terceira se refere às anomalias e complexidade do processo de mudança de Tradição de Pesquisa, bem como a mudança conceitual (PESA; OSTERMANN, 2002).

Para Laudan o progresso científico ocorre devido à confrontação e Resolução de Problemas relevantes. Sendo assim, para julgar os méritos de uma teoria ele propõe "que se pergunte se ela constitui solução adequada a problemas relevantes e não se ela é corroborada ou bem confirmada" (MASSONI, 2005, p. 33). Para Laudan (1977. apud MASSONI, 2005, p. 31) "Se uma teoria nova pode fazer tudo o que sua predecessora faz e algo mais, então a teoria nova é evidentemente superior". Deste modo, uma teoria é considerada satisfatória, quando resolve um grande número de problemas e a evolução das teorias se dá quando a nova teoria é capaz de resolver um maior número de problemas importantes.

A motivação é algo fundamental para a solução de um problema relevante. Laudan enfatiza (1989 apud PESA; OSTERMANN, 2002) que os 
cientistas têm múltiplas e variadas motivações para resolver problemas; como, por exemplo, a utilidade social associada à solução do problema, o prestígio e poder resultante para o cientista.

Segundo Villani et al. (1997), para Laudan a anomalia em Ciências da Natureza não é qualquer discordância entre teoria e os experimentos, mas a falência de uma teoria vigente em resolver problemas relevantes em um dado momento histórico, enquanto a teoria rival emergente passa a resolvê-los.

A transformação de problemas não resolvidos ou anômalos em problemas resolvidos de forma gradual constitui-se no progresso científico que conforme Colombo de Cudmani (1997), nenhum campo científico em específico é o responsável por marcar o começo de uma mudança conceitual. O progresso pode acontecer em qualquer dos diferentes campos, podendo ser através de uma mudança nas concepções, fazendo com que a nova teoria satisfaça melhor a metodologia adotada, ou uma mudança metodológica que permita uma realização mais completa das finalidades e objetivos, ou ainda uma mudança nas metas e propósitos fazendo com que os objetivos propostos inicialmente sejam irrealizáveis ou violem teorias aceitas pela comunidade científica.

Normalmente essas mudanças não ocorrem paralelamente, possibilitando uma decisão racional dos cientistas sobre qual das teorias em concorrência é a melhor. Como salienta Colombo (1997, p. 327):

\begin{abstract}
Laudan considera que o processo de mudança de paradigma não é cumulativo, mas a evolução das teorias realizada em um contexto comparativo permite ao cientista decidir entre teorias melhores que outras. Melhor em que sentido? No sentido que são mais eficazes para resolver problemas.
\end{abstract}

A racionalidade da concorrência entre as teorias e da superação de uma teoria por outra é uma característica essencial das ideias de Laudan sobre o progresso científico, e constitui a razão pela qual é considerado por alguns como sendo um epistemólogo pragmático.

Sendo assim, nessa concepção racionalista, o progresso da Ciência está ligado diretamente não à confirmação ou refutação das teorias, mas, principalmente, à sua eficiência em resolver problemas (LAUDAN, 2011). Nesse sentido, Laudan (2011, p. 18) afirma que "as teorias são relevantes, cognitivamente importantes, à medida que oferecem soluções adequadas a 
problemas importantes". Pesa e Ostermann (2002) revelam que no processo de Resolução de Problemas, a função de uma teoria é eliminar ambiguidades, diminuir irregularidades à uniformidade e demonstrar seu potencial para prever os fenômenos, perante um confronto dialético entre desafios e teorias adequadas. Pode-se destacar nas obras de Laudan que as dificuldades conceituais no modelo de solução de problemas é uma componente substantiva do progresso científico e têm bases empíricas (PESA; OSTERMANN, 2002). Tanto Stephen Toulmin, quanto Thomas Kuhn, no prefácio de sua obra "A Estrutura das Revoluções Científicas" (DAL MAGRO, 2013) reconhecem essas dificuldades conceituais.

Pesa e Ostermann (2002) argumentam ainda que o modelo de Laudan é uma sofisticação à taxonomia de problemas inicialmente proposta por Lakatos (1989), que reconhece apenas a solução do componente empírico dos problemas científicos. Acredita-se que a taxonomia de Laudan vai além, apresentando um novo componente, que são os problemas conceituais, proporcionando, dessa forma, tanto o desenvolvimento interno da Ciência quanto o desenvolvimento dos processos de ensino e de aprendizagem.

\section{PROBLEMAS EMPÍRICOS E PROBLEMAS CONCEITUAIS}

Laudan (1986), ao ampliar a esfera dos tipos de problemas existentes, propõe uma taxonomia que distingue basicamente problemas empíricos de conceituais. Os problemas empíricos são definidos por Laudan como "qualquer coisa presente no mundo natural que pareça estranha ou que, de alguma maneira, necessite de explicação" (LAUDAN, 2011, p. 22) podendo ser divididos em três tipos: I. Não resolvidos: aqueles que ainda não foram adequadamente resolvidos por nenhuma teoria; II. Resolvidos: já foram resolvidos adequadamente por alguma teoria; III. Anômalos: comportam o conjunto de problemas resolvidos por teorias rivais ou alternativas, mas ainda não foram solucionados pela teoria central da tradição de investigação.

Os problemas conceituais são definidos como aquelas inconsistências apresentadas por uma teoria. Laudan (1986) faz alusão a dois tipos de 
problemas conceituais: os internos e os externos. Os problemas internos surgem quando uma teoria se torna inconsistente, autocontraditória ou quando existe alguma ambiguidade ou circularidade na mesma; enquanto os problemas externos referem-se aos que acontecem entre teorias, ou seja, a inconsistência de uma perante a outra, ou quando a aceitação de uma teoria torna relativamente pequena aceitação da outra (LAUDAN, 1986).

Assim, pode-se dizer que a primeira classe dos problemas científicos, ou seja, classe de problemas empíricos inclui todo problema que é tomado como estranho e precisa de explicação. A segunda classe de problemas científicos, a classe dos problemas conceituais, refere-se a problemas de inconsistência apresentada em alguma teoria, tanto interna como externa. Sendo que as teorias são produtos que respondem a problemas de primeira ordem, ou seja, que respondem a perguntas de pesquisa; e os problemas conceituais são de ordem superior, podendo trazer anomalias, ou seja, a teoria existente previamente não descreve a situação, necessitando de uma teoria própria.

Em oposição ao Filósofo da Ciência Popper, Laudan (2011) não aceita a ideia de que a Ciência tem sua função nas anomalias, mas concorda que as mesmas são indispensáveis. Também não aceita que as anomalias quebrem um paradigma, como pensa o Filósofo Kuhn, pois há problemas em que as anomalias podem ser suportadas, enquanto outros casos podem comprometer a confiança na teoria. Segundo Laudan (2011), os problemas científicos são contribuições fundamentais do pensar científico e as teorias são os produtos, pois o problema produz investigações da Ciência e as teorias resultados adequados, pelo menos para alguma época.

Isso direciona a duas teses sobre a função das teorias na ciência. A primeira se refere a uma teoria ser relevante caso proporcionar soluções satisfatórias a problemas importantes. A segunda menciona a avaliação de relevância de uma teoria, ou seja, se ela resolve problemas relevantes de forma adequada, então, ou é bem confirmada ou não é corroborada. Ocorre, desta forma uma distinção entre fatos e suas explicações entre problemas empíricos e suas soluções. Mesmo que não entendido, um fato continua sendo fato, enquanto problemas empíricos são problemas conhecidos e isso está 
relacionado à concepção de mundo, podendo ser resolvido por uma teoria, pelo menos de forma parcial. Quando ocorre essa parcialidade torna-se problema anômalo, podendo vir a ser resolvido por uma teoria alternativa.

Quando se tem um conjunto de teorias em evolução que não pode ser analisada fora de seu contexto histórico e possui características metodológicas e ontológicas que dizem respeito ao grupo de regras do que é permitido fazer ou não para investigar um problema em uma determinada área do saber, fundamenta-se que há uma Tradição de Pesquisa (LAUDAN, 2011).

\section{LARRY LAUDAN E AS TRADIÇÕES DE PESQUISA}

Laudan (1987) introduz o conceito de "Tradição de Pesquisa" para compreender a natureza do conhecimento científico e o progresso da Ciência. Uma Tradição de Pesquisa, segundo ele, tem um certo número de teorias especificas que a compõem e a exemplificam parcialmente, decorre de um certo número de formulações diferentes e tem geralmente uma larga história durante um período consideravelmente longo de tempo, diferente das teorias que são de curta duração. De acordo com Ostermann et al. (2008), uma Tradição de Pesquisa é:

\footnotetext{
Um conjunto de afirmações e negações de caráter ontológico (objetivos de indagação) e metodológicos (métodos de indagação), constituindo um conjunto de pressupostos gerais acerca das entidades e dos processos de um âmbito de estudo, e acerca dos métodos apropriados que devem ser utilizados para investigar os problemas e para construir teorias do domínio (OSTERMANN et al., 2008, p. 376).
}

As tradições de pesquisas não são tendências que se constituem rapidamente, são, na verdade, historicamente consolidadas, recebem aqueles que a adotam e a fortificam ao longo do tempo. No caso, essas tradições de pesquisa e as teorias possuem condicionantes históricos e conceituais, como conjuntos de leis que corroboram empiricamente na explicação e uso de métodos acerca da natureza.

[...] toda tradição de pesquisa contém diretrizes significativas acerca da maneira como suas teorias podem ser modificadas e transformadas, 
para incrementar sua capacidade de resolver problemas (p. 130). [...] Contudo, o papel estabilizador está na tradição. As "tradições de pesquisa justificam muitas suposições feitas por suas teorias; podem servir para marcar certas teorias como inadmissíveis por ser incompatíveis com a tradição de pesquisa; podem influenciar o reconhecimento e a ponderação dos problemas empíricos e conceituais de suas teorias componentes; e podem oferecer diretrizes heurísticas para a geração ou modificação de teorias específicas" (LAUDAN, 2011, p. 132).

Asim, as tradições de pesquisa proporcionam um conjunto de diretrizes para o desenvolvimento de teorias específicas. Parte dessas diretrizes constitui uma ontologia que especifica os tipos de entidades fundamentais que existem nos comandos em que essa tradição se inscreve. A função das teorias específicas em uma tradição é a de explicar todos os problemas empíricos do domínio, reduzindo-os à ontologia da Tradição de pesquisa. Assim, a Tradição de pesquisa tem um compromisso ontológico: através dos diferentes modos em que as entidades de sua incumbência podem interagir; um compromisso metodológico, através dos modos de proceder (técnicas experimentais, modos de corroboração empírica, avaliação das teorias etc.) que são legítimos para um pesquisador que trabalha nela (OSTERMANN, 2008).

Nesta visão, Laudan (1986) afirma que há três funções importantes da Tradição de pesquisa, sendo elas: I. determinar os limites de aplicação das teorias que compõem uma área; II. proporcionar ideias iniciais que permitam a formulação de teorias explicativas, preditivas e verificáveis; e, III. justificar de maneira racional a existência de teorias científicas.

A Tradição de Pesquisa foi embasada na noção de Programa de Pesquisa de Lakatos (1989), e conserva algumas características metodológicas do mesmo, como seu caráter evolutivo e histórico. Sua evolução e historicidade surgem em um ambiente intelectual determinado, seu grau de aplicabilidade é aumentado e, posteriormente, elas se deterioram e dão lugar a novas tradições.

A Tradição de Pesquisa de Laudan, no entanto, se diferencia do Programa de Pesquisa de Lakatos no que diz respeito à sua essência, ou seja, ao núcleo firme. Para Laudan (2011), existe uma relação de flexibilidade entre o núcleo firme e o cinturão protetor ao longo do tempo. O cinturão protetor nem sempre está presente para proteger o núcleo que também pode questioná-lo. Além disso, até mesmo as teorias mais medulares da Tradição de Pesquisa sofrem a ação 
do tempo, diferente do núcleo firme de Lakatos que é protegido de modificações.

Logo, pela experiência necessariamente empírica, a Tradição de Pesquisa pode terminar com características totalmente diferentes das que apresentavam quando surgiu, situação impossível na visão de Lakatos (PRÄSS, 2008).

Dois modos básicos de produção de mudanças em uma tradição são identificados por Laudan. A primeira se refere a modificação em alguma de suas teorias específicas subordinadas enquanto a segunda menciona a mudança nos elementos nucleares mais básicos. Ou seja, o primeiro seria dos supostos centrais, que mexem com a ontologia, a visão de mundo e, então, delimitam a forma em que esse mundo deve ser estudado; o segundo seria o das teorias específicas, desenvolvidas para resolver problemas, principalmente, empíricos em domínios determinados. Esses dois modos podem entrar em conflito, gerando problemas conceituais que precisam ser resolvidos. Para Laudan (2011), uma Tradição de Pesquisa não permanece imutável, mesmo nos pressupostos mais centrais.

Para Laudan (2011) há uma evolução natural da Tradição de Pesquisa, que apresenta características de continuidade, entre uma formulação e a seguinte, pois muitos dos pressupostos centrais são conservados, porém devese tomar cuidado se uma tradição tem experimentado muitas modificações no decorrer do tempo, pois haverá muitas discrepâncias entre a ontologia e a metodologia de sua antiga formulação e da nova. Assim, olhando retrospectivamente, pareceria que não se está mais à frente da mesma Tradição de Pesquisa.

Em resumo, Laudan (2011) afirma que um aspecto importante da Tradição de Pesquisa se refere à efetividade global de uma teoria; que para isso deve-se avaliar a importância e a quantidade de problemas empíricos que a teoria resolve menos a quantidade de problemas anômalos e conceituais que a teoria gera, esta subtração resultará em progresso somente se a sucessão de teorias científicas em um domínio resultar em um grau crescente de efetividade na Resolução de Problemas (OSTERMANN; PRADO, 2008). 


\section{LARRY LAUDAN E O ENSINO DE CIÊNCIAS: ESTRATÉGIAS INVESTIGA- TIVAS}

O Ensino de Ciências, no contexto atual, depara-se com muitas barreiras como a redução da carga horária semanal disponível às aulas de Ciências, o que limita o professor ao uso de recursos e atividades diversificadas; a falta de infraestrutura nas escolas; e, o distanciamento, ou falta de contextualização entre o ensino e a aprendizagem dos conceitos teóricos, bem como a reflexão da aplicação prática para fins de aproximação deste ao cotidiano vivenciado pelos alunos.

Para isso, segundo da Silveira e Ostermann (2002) há uma tentativa de abandonar o ensino tradicional, pautado exaustivamente no ensino empiristaindutivista, ou seja, nas aulas expositivas, na aplicação de fórmulas e operações matemáticas, no uso do laboratório convencional, cujo papel, segundo Borges (2002, p. 294), "não é claro para o professor, pois o utilizam como mera ilustração de uma teoria, como mais um recurso didático". Bemfeito et al. (2008. p. 22) também apontam o uso inadequado dos laboratórios "com problemas e procedimentos previamente determinados sem possibilidades para tentativas/erros".

Vários estudos sinalizam que no Ensino de Ciências, além de trabalhar para a construção de conceitos científicos, é preciso aprender sobre sua construção (MATTHEWS, 1990; DA SILVEIRA; OSTERMANN, 2002). Utilizando a lógica, a argumentação e o pensamento crítico (GUIMARÃES; MASSONI, 2020) como ferramentas didáticas para uma melhor e mais clara compreensão de determinados conceitos, almejando uma qualificação no Ensino de Ciências da Natureza.

Sabe-se segundo Moreira (2021) que o Ensino de Física voltado à realização de testes com aplicação de fórmulas e decorar conteúdos, provoca desinteresse dos alunos. Tornando-se o "despertar o interesse" um dos grandes desafios da Física, destacada sua importância para a construção da cidadania e a base da tecnologia. Para isso, aponta-se a epistemologia de Laudan, pois utiliza a Resolução de Problemas para explicar como acontece a construção do conhecimento, através da argumentação e pensamento crítico. 
Nesta perspectiva, o ensino investigativo parte de uma pergunta que deve ser respondida e parte do levantamento de hipóteses para se chegar em uma teoria. De acordo com Azevedo (2008, p. 20), as atividades investigativas podem ser definidas "[...] como um processo, em que a investigação é desencadeada por um problema, cuja solução é motivada por uma necessidade 'cognitiva'. A investigação consiste, exatamente, na busca incessante pela solução do problema proposto".

Em outras palavras, uma proposta investigativa deve ter "[...] um problema para ser analisado, a emissão de hipóteses, um planejamento para a realização do processo investigativo, visando a obtenção de novas informações, a interpretação dessas novas informações e a posterior comunicação das mesmas" (ZÔMPERO; LABURÚ, 2011, p. 74). Um dos aspectos mais significativos dessa metodologia é a mudança de atitude que ela pode gerar tanto no estudante quanto no professor. O estudante precisa abandonar a postura passiva, de mero observador de aulas expositivas, pois pode participar do trabalho investigativo desenvolvendo habilidades como argumentação, interpretação e análise. O professor deve acompanhar as discussões dos grupos, questionar e auxiliar os alunos para que mantenham a coerência em suas ideias.

Para Sasseron (2018), o ensino por investigação deve considerar o desenvolvimento do conhecimento conceitual em conjunto com o desenvolvimento do conhecimento dos processos, por meio das informações e conceitos que os estudantes já tem trabalhado, dos problemas propostos para a investigação, da interação dos estudantes com o problema e da análise que provém das interações ocorridas em aula. Construindo assim, novos entendimentos sobre as informações que já possuem, e, por meio das análises críticas das informações obtidas na investigação, assim, desenvolverão práticas científicas e epistêmicas em estreita relação com o desenvolvimento do raciocínio científico.

Segundo Morini (2010), é possível relacionar a epistemologia de Laudan ao Ensino de Ciências a partir de três pontos: I. A identificação de um problema relevante; II. A motivação para a busca de uma solução a um problema relevante; 
III. As anomalias e complexidade do processo de mudança de Tradição de Pesquisa e da mudança conceitual.

A identificação de um problema relevante se aproxima à epistemologia de Laudan, pois sua teoria está baseada na Resolução de Problemas, e "para avaliar os méritos de uma teoria propõe que se pergunte se ela constitui solução adequada a problemas relevantes e não se ela é 'corroborada' ou 'bem confirmada" (MASSONI, 2005, p. 33).

Com relação ao segundo ponto "A motivação para a busca de uma solução a um problema relevante", aponta-se que para que o conhecimento seja construído é necessário que os estudantes estejam motivados a buscar uma solução para um problema que deve ser importante e relevante para ele (VILLANI et al., 1997). Para Pesa e Ostermann (2002), a motivação pode ter relação com diversos fatores encontrados no trabalho científico, como a busca por explicar e controlar o mundo natural, através da busca da verdade, pela utilidade social e, em certos momentos, prestígio e poder (PESA; OSTERMANN, 2002). Para Villani et al. (1997), um dos motivos que o aluno apresenta para resolver os problemas propostos é passar de ano e conseguir o diploma, o que não deixa de ser uma motivação, embora não aquela que o professor desejaria. No entanto, Morini (2010) afirma que sua busca é em relação a outros objetivos para a resolução dos problemas, "como, por exemplo, a curiosidade, a satisfação pessoal e a superação de algum conflito cognitivo que tenha surgido durante alguma atividade" (MORINI, 2010, p. 37).

Quanto ao terceiro ponto, que se refere "Às anomalias e complexidade do processo de mudança de Tradição de Pesquisa e da mudança conceitual", Laudan (2011) afirma que quando a Tradição de Pesquisa é apresentada a uma anomalia, essa não precisa ser rechaçada, assim como a tradição não deve ser aceita apenas por ter sido confirmada experimentalmente (PESA; OSTERMANN, 2002). Para Morini (2010) esse ponto remete à elaboração e ao teste de hipóteses, evidenciando que se uma suposição não funciona, é necessário que se pense em outra mostrando que a Ciência se encontra em constante evolução. Morini (2010) ainda salienta que planejar e aplicar atividades que cumpram esses requisitos não é tarefa fácil. Nessa mesma óptica, 
Villani et al. (1997) afirmam que é necessário que seja feita uma discussão entre alunos e professores para negociação quanto às tarefas didáticas e avaliações a serem realizadas nas aulas.

Santos e Goi (2012) baseadas na epistemologia de Laudan (1977) e na visão de mundo científico de Matthews (1998, 2009), trazem à tona em seu trabalho a importância da Ciência como empreendimento humano focado na resolução de situações-problema empíricas e conceituais que promovem 0 desenvolvimento teórico e experimental da Ciência, bem como promove ganhos na qualidade da cultura e vida pública dos estudantes, em virtude de terem desenvolvido competências em relação ao método científico e a Resolução de Problemas. Santos e Goi (2012) defendem a utilização da metodologia de Resolução de Problemas como uma forma de ensinar os conceitos (não a única), situando-os em seus contextos históricos e metodológicos de descoberta e de justificação, constituindo-se dessa forma, em campo metodológico e epistemológico do Ensino de Ciências. Ainda, segundo Santos e Goi (2012), temse que ter o cuidado na realização das experimentações no contexto da descoberta científica para não vincular ao método do ensino por Redescoberta ${ }^{1}$, o qual apenas promove repetições, mas se deve torná-las investigativas.

Com auxílio das reflexões de Laudan pode-se observar pontos importantes para desnaturalizar essas tendências cientificistas, ainda muito presentes no Ensino de Ciência, como por exemplo, a compreensão que a Ciência se dá em um contexto de solução de problemas; que os problemas são de diferentes ordens, empírica ou conceitual; que as teorias são elaboradas para resolver problemas existentes em uma concepção anterior e organizada de mundo que conforma uma tradição de pensamento, ou de pesquisa; que as tradições de pesquisa legitimam formas de pensar e praticar a Ciência, que no enfrentamento

\footnotetext{
${ }^{1}$ O Ensino por Redescoberta baseava-se em um conjunto de materiais elaborados por uma equipe de especialistas que procuraram introduzir um novo currículo e renovar o ensino de Ciências fazendo uma releitura das obras de John Dewey. Buscando dessa forma, formar o cidadão e preparar o trabalhador através da vivência do método científico. Para Goi (2014) os estudantes "imitam" o trabalho dos cientistas, através de roteiros passo a passo, objetivando alcançar os resultados e conclusões definidos pelo professor. Assim para Goi (2014), é nesta perspectiva de refazer passo a passo os experimentos que o Ensino por Redescoberta é criticado, pois sabemos que o aluno não consegue desenvolver-se repetindo simplesmente um roteiro de experiências (GOI, 2014).
} 
do problema científico ocorre diálogo com outras formas de conhecimentos que podem contribuir para solução do problema desde que possuam proposta conceitual.

Sendo assim, apresentar os elementos de como as tradições funcionam na perspectiva de Larry Laudan permite superar visões empírico-indutivistas presentes em professores, alunos, e, muitas vezes, em pesquisadores (HARRES, 1999; PRAIA et al., 2002), promovendo, desta forma, uma aprendizagem baseada em metodologias ativas como os Experimentos Investigativos e a Resolução de Problemas.

Pode-se assim, estabelecer um elo entre a epistemologia de Laudan e a investigação, pois, segundo estudos como de Greca et al. (2017) no que se refere à Experimentação Investigativa aliada à Resolução de Problemas, permite que os cientistas estudem o mundo natural e proponham explicações com base em evidências derivadas de seu trabalho e em relação às atividades dos alunos Ihes permitam compreender ideias científicas e a forma como os cientistas estudam o mundo natural. Em ambos os casos a investigação envolve um processo de diagnóstico intencional de problemas, crítica de experimentos e distinção de alternativas, planejamento de pesquisa, validação de suposições, busca de informações, construção de modelos, discussão em grupos e construção de argumentos coerentes. Portanto, conforme Greca et al. (2017), com o uso da investigação pretende-se que os alunos, além de construírem conhecimento significativo sobre o mundo natural, desenvolvam habilidades e uma compreensão do processo, o que Ihes permitirá adquirir uma visão mais apropriada da Ciência.

Magalhães et al. (2020) relatam em sua pesquisa que ao analisar o desempenho de estudantes das Séries Iniciais do Ensino Fundamental quanto às habilidades e atitudes desenvolvidas durante o estudo do conceito de calor $\mathrm{e}$ seus efeitos para produzir mudanças de estados nas substâncias, concluíram que a atividade experimental e a reflexão crítica dos dados possibilitou a percepção que a substância não deixa de existir ao mudar de fase, mas passa a outro estado de agregação molecular. Isso implica aprender a lidar com os erros e com a incerteza do conhecimento. Ainda, segundo essa análise, Magalhães et 
al. (2020) destacam que atividades investigativas não visam 'depositar' nos estudantes os conceitos, mas problematizá-los. Fazê-los perceber a necessidade de criticar as evidências e não ter o conhecimento como algo pronto e acabado. Todavia, as atividades experimentais podem ajudar os estudantes a construir conceitos como o da conservação da matéria, nas transformações de estado, que dificilmente aprenderiam espontaneamente sem uma intervenção planejada.

Para Fernández e Greca (2014) a possibilidade de o estudante apresentar uma melhor compreensão dos conceitos científicos propostos após poder experimentá-los de forma prática e chegar à resolução de um problema, constitui um marco de ligação entre a Experimentação Investigativa e a epistemologia de Laudan. Para isso, ainda conforme Fernández e Greca (2014), recomenda-se influenciar o Ensino de Ciências por investigação desde as Séries Iniciais, bem como que os professores sejam capazes de transmitir emoção no conhecimento da Ciência, para que possam atrair o interesse e a motivação, condições necessárias para a participação ativa dos alunos do Ensino Fundamental.

\section{CRÍTICAS A EPISTEMOLOGIA DE LARRY LAUDAN}

Segundo alguns estudos, pode-se encontrar certas apreciações críticas ao modelo de Resolução de Problemas de Laudan. Por exemplo Sanches (2000) que revela em sua pesquisa em História e Filosofia da Ciência que apesar do trabalho louvável de Laudan desenvolvido na obra "Progresso e seus problemas " (1977), existem, no entanto, alguns aspectos importantes que podem ser observados.

Sanches (2000) denomina esses aspectos por "pontas soltas", sendo elas: i) problemas versus problemas; ii) uma visão abertamente instrumental ou individualista do "progresso" e"Tradições" e, iii) de como identificar quem constitui a elite científica.

Quanto aos problemas versus problemas, Laudan (1986) instituiu em sua obra "Progresso e seus Problemas", um critério de avaliação. 
A eficácia geral de uma teoria na resolução de problemas é determinada avaliando a quantidade e a importância dos problemas empíricos que a teoria resolver e subtrair dela a quantidade e importância das anomalias e problemas conceituais que a teoria gera. (LAUDAN 1986, p. 102)

Para Sanches (2000), Laudan explicou claramente que a Ciência também é fundamentalmente uma atividade de Resolução de Problemas, diferenciando com clareza, os tipos de problemas que devem ser abordados, ou seja, os problemas empíricos e conceituais, e quando os mesmos deixam de ser tais. O que parece que ele não deixou claro foi a questão de esclarecer o número de problemas que a teoria resolve. Se por um lado revela como identificar problemas, por outro não traz um princípio guia, para colocar uma luz vermelha quando esses problemas são irritantes e perniciosos.

Isto leva a pensar que se deve supor que o número de problemas que uma teoria resolve é infinita e que sua caracterização se enquadra na esfera da intuição vigente. Fica-se com a impressão de que Laudan (1986) cai na mesma teia que com tanta dedicação queria desmantelar. Sanches (2000) ainda lembra de que Laudan (1986) questionou repetidamente a Kuhn o fato de que ele não esclareceu por que ante a $X$ anomalias um paradigma não é suportado, mas que quando confrontado com outra situação anômala $X$ relevante, decide desistir de um paradigma.

Outro argumento crítico de Sanches (2000) é que se Laudan fosse questionado sobre em que situação $X$ se pode decidir que um problema atingiu seu ponto crítico, se observaria que, para Laudan, quando se aceita uma teoria, não se a adota com o propósito de buscar verdades importantes sobre o mundo, se não, para resolver um problema específico sobre um determinado aspecto específico do mundo.

Com relação à uma visão abertamente instrumental ou individualista do "progresso" e das "tradições", Sanches (2000) reporta que Laudan (1986) insistiu na noção de "progresso" em vez de racionalidade, tentando encontrar um ponto de convergência, ou seja, uma atividade científica, pois, para Laudan (1986) é racional quando se encontram soluções cada vez mais frutíferas para problemas que estão na mira de uma tradição particular. 
Laudan (1986) escreve:

\begin{abstract}
O progresso pode ocorrer se e somente se, há sucessão de teorias científicas em um domínio de amostra; aumento do grau de eficácia na resolução de problemas [...] quando modificamos uma teoria ou a substituímos por outra, essa mudança é progressiva se, e somente se, a versão posterior resolver os problemas de forma mais eficaz do que seu antecessor (LAUDAN, 1986, p. 102).
\end{abstract}

Conforme Sanches (2000), como a única coisa que conta é "resolver problemas" e com isso existem diferentes maneiras de ver o mundo, causa diferentes tipos de problemas, com a busca de soluções. Este fato traz uma ameaça de cair em um individualismo; em que cada pesquisador pode erguer suas próprias teorias para resolver seus problemas. Bem, no final das contas, o que conta é "produzir progresso", escolhendo a teoria mais efetiva.

Por outro lado, Laudan (1986) tem uma visão que é instrumental ou tradições individualistas, indicando que os cientistas podem aceitar ou rejeitar tradições concorrentes com base em seus sucessos ou evidências empíricas que eles mostraram ter sob seu cinturão. Laudan reconhece pluralidade, historicidade e critérios de racionalidade, dependentes de cada Tradição de Pesquisa. No entanto, ele não se compromete com a ideia de uma meta tradição universal, na Ciência não há critérios estabelecidos para avaliar teorias. Dentro de sua noção da dinâmica das tradições, Laudan (1986) destaca a possibilidade de diálogo e debate, ressaltando que o exercício dessa troca pode ocorrer não apenas dentro uma tradição, mas também entre tradições de diferentes origens.

Portanto, de acordo com Laudan (1986) não existem tradições "arquetípicas" de comunidades científicas, mas como alternativas instrumentais para a realização dos propósitos da Ciência: A Resolução de Problemas em termos de boas explicações e previsões.

A terceira ponta solta, referida por Sanches (2000) "Como identificamos quem constitui a elite científica? "A noção eficientista do progresso e mais influente na História da Ciência. Segundo Laudan (1986) sua ambiguidade. Para Sanches (2000) Laudan não concebe as tradições como constitutivas de comunidades científicas, mas como meras alternativas instrumentais que permitem atingir determinados objetivos. 
Então, é percebida dentro dos critérios "Meta-intuitivo" de Laudan (1986) uma aparente ambiguidade, a saber: (a) por um lado Laudan evita por todos os meios em falar de uma "comunidade científica" [fixa] "arquetípica". Neste sentido, como é visto, Laudan, critica em Kuhn sua noção de "Ciência normal" e em Lakatos a "Ciência madura." Mas, por outro lado, (b) fala de uma "elite científica" responsável por estabelecer casos-padrão de racionalidade científica. As intuições da "elite científica" são decisivas na medida em que selecionam os casos o "padrão" o grau de adequação de uma teoria de avaliação científica é proporcional ao número de intuições preferidas (IP) às quais você pode fazer justiça. (LAUDAN, 1986, p. 206).

Tem-se a impressão de que Laudan (1986) usa a noção de "elite científica" para não falar de "comunidade científica" por duas razões: a primeira Laudan (1986) inadvertidamente comenta de consenso, em que revela que uma ampla maioria da elite deve concordar com os casos paradigmáticos de racionalidade científica, a segunda tem que haver consenso sobre como eles deveriam descrever os episódios que constituem casos padrão.

Os membros de uma elite científica podem estar de acordo, por exemplo, de que a transição da teoria "geocêntrica" para "heliocêntrica" era progressiva, mas pode ter pontos de visões diferentes sobre o conteúdo das teorias mencionadas. Conforme Sanches (2000) um dos argumentos mais fortes expostos, no século XVI, contra o sistema copernicano consistia em apontar que tal teoria, embora talvez adequada na medida em evidências astronômicas, era inaceitável porque infringia os princípios da Física mais bem estabelecida.

\section{CONSIDERAÇÕES FINAIS}

Observou-se ao longo da composição desse manuscrito que a epistemologia de Laudan está entre as epistemologias racionalistas mais estudadas e em desenvolvimento do século $X X$ e $X X I$, que contestando a visão cientificista, representa uma contribuição significativa para a Filosofia da Ciência e para o Ensino de Ciências, também neste início de milênio. Apesar das críticas à epistemologia do autor, permite perceber as divergências epistemológicas e 
de seus problemas conceituais. Pode apontar que sua evolução abriu novas áreas na Ciência e suas rupturas com o mundo clássico e continua gerando progresso científico e filosófico.

Mesmo tendo críticas sobre sua forma de avaliar os problemas, progresso científico e tradições da Ciência, observa-se que as concepções de Larry Laudan apontam para a consolidação de um embasamento teórico mais elaborado sobre a atividade científica, trazendo critérios importantes para a construção de aulas mais contextualizadas e sistematizadas sobre Ciências com modelos de ensino e aprendizagem frutíferos e eficientes.

Outro ponto que vale destacar, nas concepções de Laudan, é a Resolução de Problemas empíricos e conceituais como molas mestras para 0 desenvolvimento científico e resultado final para e elaboração de teorias. Considera, também, que o progresso da Ciência resulta da resolução desses problemas e que a troca de teorias científicas não é cumulativa, a regra é a coexistência de teorias rivais. Assim, a Ciência está sempre em busca de teorias que possam resolver a maioria dos problemas empíricos e reduzir os problemas conceituais. Sendo que, o progresso científico ocorre quando novas teorias conseguem resolver mais problemas que suas antecessoras.

Sendo assim, pode-se concluir que as reflexões sobre Laudan levam os estudantes a uma aprendizagem dos conteúdos, possibilitando aos mesmos, relacionar os conteúdos adquiridos no âmbito escolar com sua prática social, podendo atuar na sociedade em que estão inseridos de forma autônoma e crítica.

\section{REFERENCIAS}

AZEVEDO, M. N. Pesquisa-ação e atividades investigativas na aprendizagem da docência em Ciências. 2008. 224 f. Dissertação (Mestrado - Programa de Pós-Graduação em Educação. Área de Concentração: Ensino de Ciências e Matemática) - Faculdade de Educação, Universidade de São Paulo, São Paulo.

BEMFEITO, A. P. D. et al. Ondas de rádio no ensino médio com ênfase CTS. 2008. Tese de Doutorado. Dissertação de Mestrado Profissional, PPECM/CEFET/RJ, Rio de Janeiro, 73 p. 
BORGES, A. T. Novos rumos para o laboratório escolar. In: Caderno brasileiro de ensino de Física. v.19, n.3: p.291-313, dez. 2002.

BRAUNSTEIN, G.K. O estabelecimento da tradição de investigação mendeliana sob a perspectiva epistemológica de Larry Laudan. ENCONTRO NACIONAL DE PESQUISADORES EM EDUCAÇÃO EM CIÊNCIAS - ENPEC, 8. Águas de Lindóia. 2011. Anais... ABRAPEC: Águas de Lindóia.

COLOMBO DE CUDMANI, L. Historia y Epistemología de las Ciencias. Enseñanza de las ciencias, Barcelona, v. 17, p. 327-331, 1997.

DAL MAGRO, T. Critério de decisão entre hipóteses científicas Rivais: Kuhn, Lakatos e

Laudan. Cognitio-Estudos, São Paulo, v. 10, n. 2, p. 174-190, 2013.

FERNÁNDEZ, D. P.; GRECA, I. M. Uso de la metodología de la indagación para la enseñanza de nociones sobre fuerza sen primer ciclo de la escuela primaria. Revista Enseñanza de la Física. v 26, n 2, p.265-273, 2014.

GOI, M. E. J. Formação de professores para o desenvolvimento da metodologia de resolução de problemas na educação básica. Tese apresentada ao Programa de Pós-Graduação em Educação da Faculdade de Educação da Universidade Federal do Rio Grande do Sul. Porto Alegre, RS. 2014.

GRECA, I. M.; JESÚS A. M.; VILLAGRÁ, J. A.; DIEZ OJEDA, M. La formación em ciencias de los estudiantes del grado en maestro de Educación Primaria. Revista Electrónica de Enseñanza de las Ciencias, v 16, n 2, p. 231-256. 2017.

GUIMARÃES, R. R.; MASSONI, N. T. Argumentação e pensamento crítico na educação científica: análise de estudos de casos e problematizações conceituais; Revista Brasileira de Ensino de Ciência e Tecnologia, v. 13, n. 2, p. 320-344. 2020.

HARRES, J. B. S. Uma revisão de pesquisas nas concepções de professores sobre a Ciência da Natureza e suas implicações para o ensino. Investigações em Ensino de Ciências. IENCI, v 4 (3), pp 197-211. 1999.

KUHN T. La estructura de las revoluciones científicas. México: Ed. Fondo de Cultura Económica, 1971. 
LAKATOS, I. La metodología de los programas de investigación científica. Ed. Alianza. Madrid, 1989.

LAUDAN, L. El progreso y sus problemas. Hacia uma teoria del crecimiento científico. Ediciones Encuentro. Madrid, 1987.

El progreso y sus problemas. Hacia una teoria del crecimiento científico. Ediciones Encuentro. Tradução para o espanhol do original Progress and its problems, Madrid, 1977, University of California Press, 1986.

O progresso e seus problemas: rumo a uma teoria do crescimento científico. Tradução R ed. São Paulo: EdUNESP, 2011.

O Progresso e seus Problemas: rumo a uma Teoria do Crescimento Científico. Tradução de Roberto Leal Ferreira; São Paulo: UNESP, 2010.

MAGALHÃES, A.; PHILIPE. C.; VILLAGRÁ, J. ANGEL. MENESES.; GRECA, I. M. Análise das Habilidades e Atitudes na Aprendizagem Significativa Crítica de Fenômenos Físicos no Contexto das Séries Iniciais. Ciência \& Educação, Bauru, v. 26, 2020.

MASSONI, N. T. Epistemologias do século XX. Em M. A., Moreira e E. A., Veit. In: Textos de apoio ao professor de física, 16 (3), Porto Alegre: UFRGS, Instituto de Física, Programa da Pós-Graduação em Ensino de Física, 2005.

MOREIRA, M.A.; MASSONI, N. T. Epistemologias do século XX. São Paulo: Editora E.P.U, 2011.

MORINI, L. B. M. Atividades experimentais de Física à luz da epistemologia de Laudan: ondas mecânicas no ensino médio. 2009. Dissertação (Mestrado Profissional em Ensino de Física) - Universidade Federal do Rio Grande do Sul, Porto Alegre, 2010.

NICKLES, T. Historicist Theories of Scientific Rationality. The Stanford Encyclopedia of Philosophy, 2017. Disponível em: de https://plato.stanford.edu/entries/rationality-historicist/\#HistConcRatiBattBigSyst Acesso em: 18 de novembro de 2020.

OSTERMANN, F. A epistemolgia de Kuhn. Caderno Catarinense de Ensino de Física, v. 13, n. 3, p. 184-196, 1996. 
OSTERMANN, F. et al. Tradição de pesquisa quântica: uma interpretação na perspectiva da epistemologia de Larry Laudan. Revista Electrónica de Enseñanza de las Ciencias, v. 7, n 2, p 366-386, 2008.

PESA, M. A.; OSTERMANN, F. La ciência como actividad de resolución de problemas: la epistemologia de Larry Laudan y algunos aportos para las investigaciones educativa en ciências. Cad. Bras. Ens. Fís., v. 19, n. 2002, p. 84-99, 2002.

PRAIA, J. F.; CACHAPUZ, A. F. C.; GIL-PÉREZ, D. Problema, teoria e observação em Ciência: para uma reorientação epistemológica da educação em Ciência. Ciência e Educação, São Paulo, v. 8, n. 1, p. 127-145.2002.

PRASS, A. R. Epistemologias do século XX. Dissertação de mestrado para a Pesquisa em Ensino de Física. Universidade Federal do Rio Grande do Sul, Porto Alegre, 2007/2.

SANCHES, E. B. Algunos comentários críticos a La meta-metodología de Larry Laudan. Tesis que para obtenerel grado de Maestro em Historia y Filosofia de La ciência. Universidad Autonoma Metropolita Unidad de Iztapalapa. Division de Ciencias Sociales e Humanas. México. 2000.

SANTOS, C. A. G. A falência dos modelos normativos de filosofia da ciência-a astrologia como um estudo de caso. Tese de Doutorado. PUC-Rio, 2006.

SANTOS, F. M. T.; GOI, M. E. J. Resolução de Problemas no Ensino de Química - fundamentos epistemológicos para o emprego da metodologia na Educação Básica. XVI Encontro Nacional de Ensino de Química (XVI ENEQ) e X Encontro de Educação Química da Bahia (X EDUQUI) Salvador, BA, Brasil. V. 1 p. 1 a 11. 2012.Anais....2012.

SASSERON, M. H. Ensino de Ciências por Investigação e o Desenvolvimento de Práticas: Uma Mirada para a Base Nacional Comum Curricular. Revista Brasileira de Pesquisa em Educação em Ciências. RBPEC 18(3), 1061-1085. Dezembro, 2018.

SILVA, É. R. Á. da. Articulação entre resolução de problemas e a temática drogas como proposta metodológica para o ensino de química. Trabalho de Conclusão de Curso no formato de artigo apresentado como requisito parcial para obtenção do título de Licenciada em Ciências Exatas -Unipampa-Caçapava do Sul-RS. 2017. 
SILVEIRA, F. L.; OSTERMANN, F. A insustentabilidade da proposta indutivista de "descobrir a lei a partir de resultados experimentais". Cad. Bras. Ens. Fís., v. 19, número especial: p.7-27, jun. 2002.

VILLANI, A. Contenido científico y problemática educacional em la formación de profesores de ciencias, 1986. Tesis (Libre docencia) - Instituto de Física, Universidade de São Paulo.

ZÔMPERO, A. F.; LABURÚ, C. E. Atividades investigativas no Ensino de Ciências: aspectos históricos e diferentes abordagens. Revista Ensaio, Belo Horizonte, v. 13, n. 03, p. 67-80, 2011.

Recebido em: 16/01/2021

Aprovado em: 23/09/2021 